Journal of Computer Science 6 (12): 1531-1534, 2010

ISSN 1549-3636

(C) 2010 Science Publications

\title{
A System for Payroll Management
}

\author{
${ }^{1}$ Pavitra Rani Gautam, ${ }^{1}$ Sugadev Ragumani and ${ }^{2}$ Y.K. Sharma \\ ${ }^{1}$ Department of Bioinformatics, \\ ${ }^{2}$ Department of Biostatistics, \\ Defense Institute of Physiology and Allied Science, \\ Defense Research and Development Organization, \\ Ministry of Defense, Lucknow Road, Timarpur, Delhi, 110054, India
}

\begin{abstract}
Problem statement: This research had done the software design and database system model for Payroll Management System (PMS) in Defense Institute of Physiology and Allied Sciences (DIPAS). The calculations are based on the user provided employees details like basic pay, house rent allowance, loan details and so on. Based on these user inputs the system automatically generates pay slip, pay bills, all schedules for debit and credit payments. This system is developed in such a way to suit for both new and old pension schemes of the central government employees of India. The use of Java Server Pages (JSP) language for system development allows easy modification of the system design. So the system design can be directly implemented to any other central government organization with slight modifications. Approach: This study presented the database and software design for PMS. The software changes the manual operation into a computer-based system to automate study, provide efficiency, accuracy, timelessness, security and economy. Results: After undertaking an in-depth examination of the existing manual payroll management system and analyzing its short comings, it has been found necessary to remove its deficiencies and provide a suitable solution for presently encountered problem. Conclusion: The proposed system can help the organization to manage efficiently the employee pay related data as personal information, salary information, loan information and so on.
\end{abstract}

Key words: Payroll Management Software (PMS), New Pension Scheme (NPS), JSP, database, Structured Query Language (SQL)

\section{INTRODUCTION}

Information and database system projects are initiated to improve the accuracy of the processing data and ensure the procedure prescribing how to do a specific task. A computer program can maintain accurate and consistent database, hence resulting is an improved performance. The program efficiency can be increased considerably by including automatic calculations and fast data retrieval capabilities. This will dramatically reduce the manual error and permit more study at lower cost and effort.

Defense Institute of Allied Sciences (DIPAS) is a large organization, consisting of different cadres like Scientists, Technical staffs, Admin staffs and Service officers and so on. The administration section is maintaining the pay records of all the DIPAS employees. One of the main jobs of admin section is to generate pay roll for all the employees and their payment reports. Due to the non-availability of a proper database management system all the data is handled manually. Because of large volume of payroll data and calculations, it is very difficult to handle the data manually and delayed the pay roll process. This created an immediate need to develop a new computer based pay roll data base system to avoid the delay in generating pay bills, loan schedules, payment reports, pay slips and so on. So this new Pay roll Management System (PMS) is developed in DIPAS as an internal project.

Database description: The centralized database structure of PMS minimizes the labor and time. This database provides the proper data input forms with self descriptive labels and consist of inter-related modules for better summaries. It also optimizes the computer

Corresponding Author: Pavitra Rani Gautam, Department of Bioinformatics, Defense Institute of Physiology and Allied Science, Defense Research and Development Organization, Ministry of Defense, Lucknow Road, Timarpur, Delhi, 110054, India Tel: +91 01123883185 Fax: 011-23914790 
resources by proper utilization of available space by removing the duplication of files and records. These features remove the possibility of data redundancy and generate accurate and error free monthly pay bills, pay slips and all type of schedules This database can also be accessed through on-line system. The main advantage of the PMS database is, minimizing the amount of input requirements, avoiding delay, controlling errors and keeping the steps simple. It provides the modules for insertion, data update, deletion, pay slips, pre-pay bill and loans details. This user friendly system can directly implemented on the server environment. Furthermore, this comprehensive database facilitates fast on line data upload, data retrieval and reports generation.

System description: The new system is simple in its structure and operations. The operation procedures are easily understandable and sufficiently flexible to cope with future requirements (Connolly and Begg, 2004; Ahmad et al., 2010). The new requirements can easily incorporate in the system without the need for redesign the whole system. It is a user friendly menu driven system. So that the data entry operator can easily enter data and management can get the pay reports in timely basis. PMS is capable of minimizing the data redundancy which frequently occurs in non-computerized system (Ahmad et al., 2010; Noraziah et al., 2008 Muslih and Saleh, 2010) and it is enable the management to get reports for making quick decision, which is not possible in the existing manual system. This study is developed using Java Server Pages (JSP), TOMCAT, JAVA, JAVA SCIRPT and SQL Server. The JSP is selected for this study for the following reasons like portability, efficiency, robust, independency of layers and easy integration with other sources Java Database Connectivity (JDBC) and so on (Xavier, 2006; Schildt, 2002).

\section{MATERIALS AND METHODS}

Before designing the PMS, necessary objectives of the system were established. The objectives were created after the detailed analysis of organization structure, limitations and concerns in the existing manual system. The various necessary details in the report generation also gathered from the concerned authorities. This helped us to plan an effective PMS system. Based on the retirement pension scheme, DIPAS employees were divided as Regular (REGULAR) and New-Pension-Scheme (NPS) employees. Based upon cadre the employees were divided into four categories as Defense Research
Developmental Service (DRDS), Defense Research Technical Council (DRTC), Administrative staffs (ADMIN) and All Lab Service (ALS). The combination of both pension scheme and cadre lead us to divide all the employee record into eight different categories corresponded to eight tables. But the NPS data for DRTC, ADMIN and ALS have the same record table format. This reduced the number of tables to be maintained reduced from eight to six.

System analysis: The system development mainly requires quick paybill generation. Further, this process should not be delayed by the data accumulation. So the process requirements of the system were completely analyzed and documented. All the data processing including addition, deletion and editing permission is given to only two users, 1 and 2. Among the six tables, user1 can process the data of DRDS Regular and DRDS-NPS. The remaining data tables will be processed by the User 2 (Fig. 1).

Logical design: A database management system allows the organization to structure its information, so users can retrieve data, update data, generate reports and so forth, in a flexible manner as well as prevent the users against unauthorized access. The database management system helps organization to organize or structure their data in a logical way. This concept of database management system is applied in PMS for data accessibility.

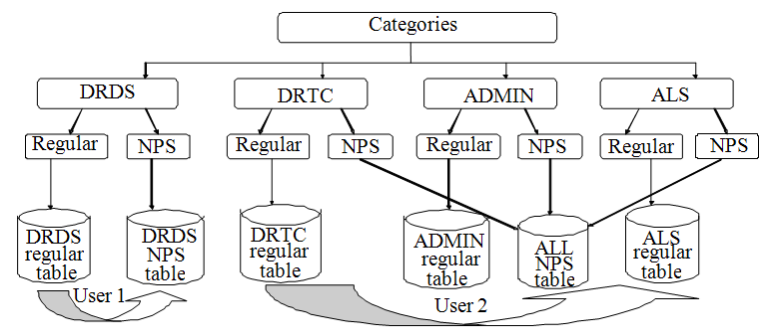

Fig. 1: Categories: Table access

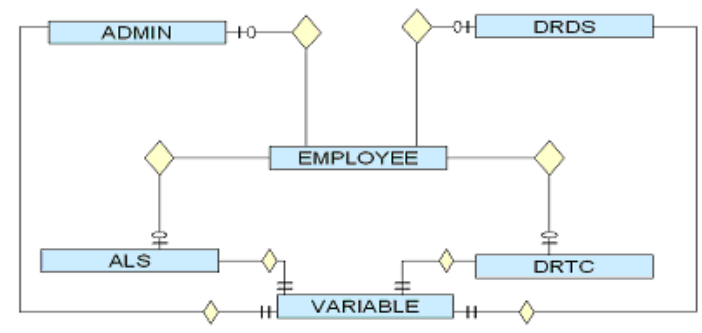

Fig. 2: ERD for PMS 
Among the conceptual, logical and physical database models, our design is based on logical database for system design. This database method is mostly used in design because it helps in establishing a simple data Entity Relationship (ER) models (Date, 2003). The developed ER model for PMS is shown in the diagram (Fig. 2).

\section{RESULTS}

The PMS have two separate packages of modules for DRDS and DRTC. Both the users have their own user Id and Password. Both the package has the same nine sub modules listed as:

- Available id module

- Change and show variables module

- Pay bill module

- Add employee module

- Update employee module

- Delete employee module

- Pay slip module

- Add loan module

- Schedule generator module

Basic pay roll related information of the newly joined employees can be easily added into the data base using the Add Employee form. Using this form user can enter the basic employee information like Id, Name, Basic Pay, Grade Pay, Designation, Insurance, Deduction and all other details, in the designated text field as shown in (Fig. 3).

All light background fields are compulsory fields to be field. The up gradation of the exiting employee record details can be done using the Update Employee Module.

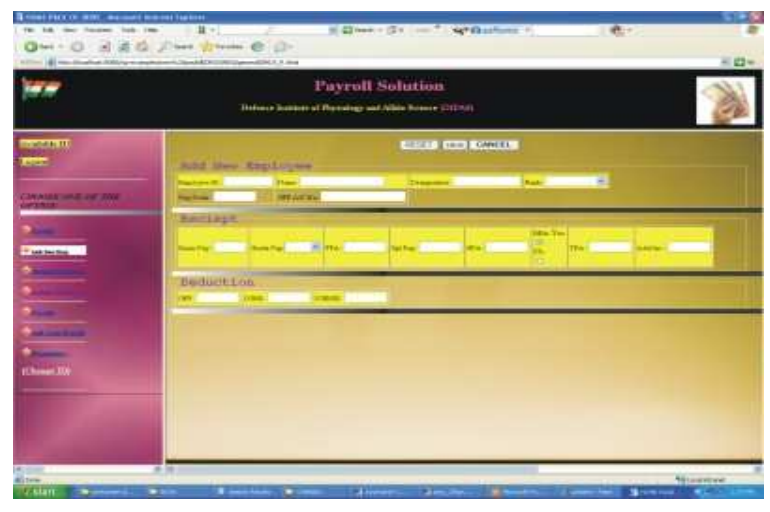

Fig. 3: Add new employee form
The employee Add Loan Module can be used to enter all the loan details of the employees into the database. The loan details like total loan amount, total installments, paid installments and balance information of the employees, from different cadre can be entered.

\section{DISCUSSION}

Add new employee: This module provides the facilities to a user for the adding new record. Before adding a new employee record user must check the available ID in the respective cadre.

Change and show variables: This will change the DA and HRA rate and will also show the current DA and HRA rate.

Delete employee: Sometime the situation arises due to which we have to delete the particular Employee record from our database, for example when an employee get retired, transferred somewhere else, leave the organization and so on. In this situation we have to delete the record of particular employee, the Delete Employee module provides this facility.

Update employee: When the user wants to update the information as Grade pay, Basic Pay, Designation, any Miscellaneous either deduction or credit., of an existing Employee, using Update Employee Module he can do that as shown in (Fig. 4).

Pay slip: This module is used to generate the Pay slips of all Employees of the current Month.

Add loan details: When an Employee take loans from the organization, then his loan details must be filled in the loan detail Module so the deductions from his salary can be done correctly. Using Loan Module user can do all loan related calculation in very fast and easily manner.

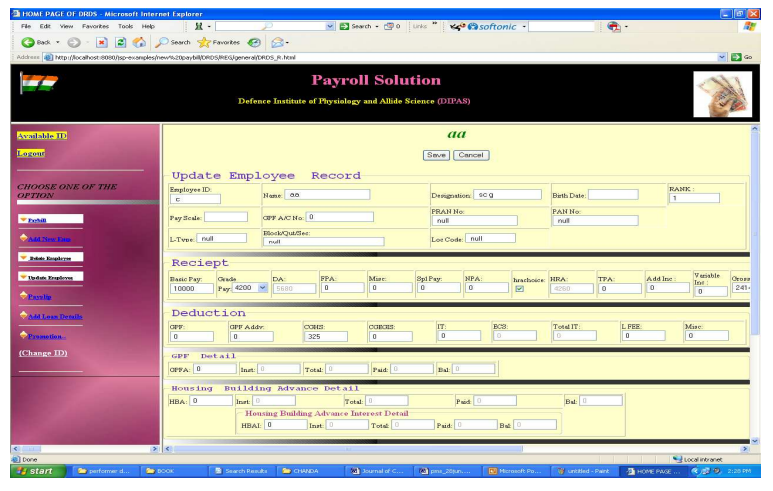

Fig. 4: Update employee record form 


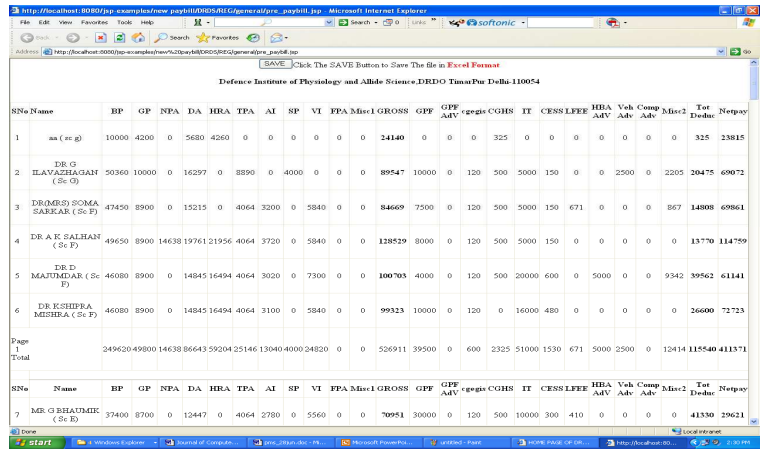

Fig. 5: DRDS pay bill report

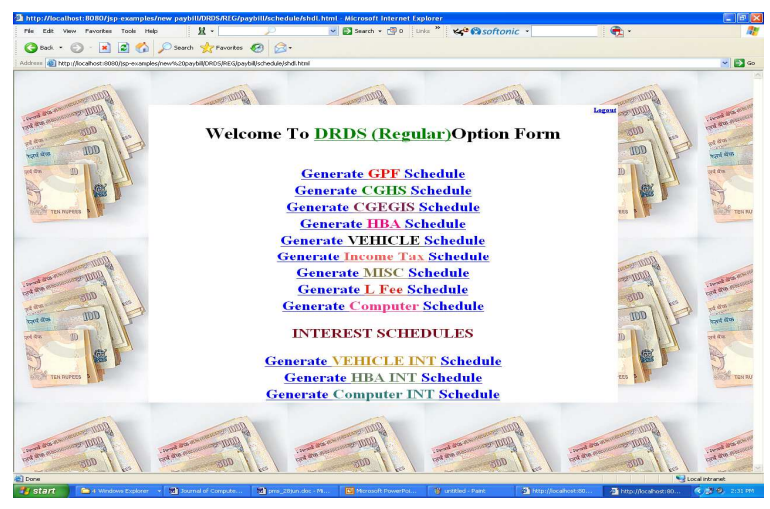

Fig. 6: Schedule generator page

Paybill: This module will generate the paybill for the current month (Fig. 5).

Generate schedules: After generating the paybill user must need to generate schedules for all heads deductions as well as credit. This module provides the facility to generate all schedules. In case of loan for principal and interest amount there are separate links as shown in (Fig. 6).

\section{CONCLUSION}

In this study a comprehensive database PMS system for the DIPAS employees is introduced. The study elaborates the system analysis, software and database design and system development. PMS is able to store huge data of the employees and generate reports according to the need. In addition, PMS effectively controls the data in a user-friendly manner. It also enables the user to access, update and delete data in a flexible manner.

\section{REFERENCES}

Ahmad, N., N. Khan, A.N.A. Alla and A.H. Beg, 2010. A novel database design for student information system. J. Comput. Sci., 6: 43-46. DOI: 10.3844/jcssp.2010.43.46

Connolly, T.M. and C.E. Begg, 2004. Database System: A Practical Approach to Design, Implementation and Management. 4rd Edn., Addison Wesley, USA., ISBN: 10: 0321210255, pp: 1236.

Date, C.J., 2003. An Introduction to Database System. 8th Edn., Addison Wesley, USA., ISBN: 10: 0321197844, pp: 1024.

Muslih, O.K. and I.H. Saleh, 2010. Increasing database performance through optimizing structure query language join statement. J. Comput. Sci., 6: 585-590. http://www.scipub.org/fulltext/jcs/jcs65585590.pdf

Noraziah, A., R. Norhayati, A.N. Abdalla, A.H. Roslina and M.A. Noorlin et al., 2008. A novel database system model design for tender management system. J. Comput. Sci., 4: 463-466. DOI: 10.3844/jcssp.2008.463.466

Schildt, H., 2002. Java 2: The Complete Reference. 5th Edn., McGraw-Hill Osborne Media, USA., ISBN: 0070495432, pp: 1184.

Xavier, C., 2006. Web Technology and Design. 1st Edn., New Age International Publishers, New Delhi, ISBN: 8122414508, pp: 388. 